Journal of the Rubber Research Institute of Sri Lanka, (2007) 88, 77-87

\title{
Can tapping panel dryness of rubber (Hevea brasiliensis) be minimised at field level with better management?
}

\author{
A M W K Senevirathna*, S Wilbert*, S A P S Perera* and \\ A K H S Wijesinghe*
}

Received 15 February 2007: Accepted 07 June 2007

\begin{abstract}
This study attempted to find the significance of tapping panel dryness (TPD) of extensively grown new clones in Sri Lanka, with a view to find possible ways to minimise or overcome this disorder at field level. A survey done for clones RRIC 100, 102, 121 and 130 showed that the incidence of TPD was high when tapping is done in renewed bark compared to that of virgin bark and it increased with the advancement of the tapping panel from B0-1 to B1-2. Also, \% TPD increased with age, immature period, girth of plants, yield and with high intensity of tapping. Generally, the \% TPD (partial + full) was high in RRIC 100 (22.5\%) and RRIC 102 (19.7\%) clones compared to the other clones surveyed. On average in any clone, $40 \%$ of the dry trees were with a partial dryness. The estimated average yield loss per tapping panel of RRIC 100 was ca. $20 \%$ and for the other clones surveyed it was ca. $15 \%$.

Morphologically, the majority of the TPD affected trees were without external symptoms (52\%), whilst very few (3\%) was with abnormal out growth on the trunk and the rest was with bark necrosis, which is irreversible. Since the TPD incidence was high in shallow areas $\left(<10^{\circ}\right.$ land gradient) where water logging and occasional floods occur, such areas should be avoided in planting of rubber in future. Good quality planting material should also be used and the immature upkeep should be of good quality to minimise the immature period and any plant stresses. Implementation of low frequency tapping systems will also be helpful in controlling this disorder.
\end{abstract}

Keywords: fully dry, partial dry, physical factors, tapping panel dryness, TPD

\section{Introduction}

Productivity level of rubber (Hevea brasiliensis Muell Arg.) plays a key role in overall profitability of a plantation. The level of productivity varies considerably from plantation to plantation due to various factors such as differences in genotypes, agronomic practices, climate etc. Some yield determinants are not clearly understood; and one of such causes for the decline in latex production is the tapping panel

* Rubber Research Institute of Sri Lanka, Dartonfield, Agalawatta, Sri Lanka. 
Tapping panel dryness of rubber

dryness (TPD); a physiological disorder, which ultimately results in decline or complete cessation of latex production. The actual mechanism of this disorder is not yet clearly known. TPD has basically been categorised into two, i.e. reversible and irreversible dryness (Jacob et al., 1994) depending on the symptoms of latex production. However, symptoms of TPD in terms of morphological features and nature of latex production are rather complicated and shown as partial dryness, full dryness, dryness with bark out-growth and bark cracks and recovered dry trees etc. No studies have been concentrated on the characterisation of these different types of TPD and the associated factors.

Furthermore, the clonal differences in susceptibility to TPD had been reported in early recommended clones (de Soyza et al., 1983; Gohet et al., 1997; Omokhafe and Aniamaka, 2000 ) with the high yielding clones are more susceptible to TPD than the low yielding nubber clones (Gohet et al., 1997). However, the genotypic susceptibility to TPD at early stages of growth or characterisation of different types of TPD in newly recommended, high yielding, extensively grown clones in Sri Lanka is not well understood. Therefore, the identification and characterisation of effects of different types of TPD and associated physical factors are important in future planting programmes, to recommend possible remedies and ultimately to enhance the productivity and profitability of rubber plantations. This study was aimed to find the significance of tapping panel dryness in latex production and key physical and plant factors associated with genotypes that are extensively grown in Sri Lanka and to find possible remedies to minimise or overcome this disorder.

\section{Materials and Methods}

Four of popular high yielding rubber clones in the commercial plantations namely RRIC 100, 102, 121 and 130 were selected from the estates in the Kalutara region of the low country wet zone of Sri Lanka for a survey. Based on the availability of these clones, five different fields from each clone and tapping panel $\mathrm{B} 0-1$ (A), B0-2 (B), B1-1 (C) and B1-2 (D) were selected from five estates. Two adjacent tapping blocks (a tapping block consisted of 275-400 trees) tapped by two tappers were selected from each clone under each tapping panel (Table 1). In cases where there was no enough number of replicates, the entire number of fields available was taken for sampling. 
A M W K Senevirathna et al.

Table 1. Number of tapping blocks and number of trees surveyed from each tapping panel and clone

\begin{tabular}{lccc}
\hline Clone & Tapping panel & $\begin{array}{c}\text { No. of tapping } \\
\text { blocks }\end{array}$ & No. of trees \\
\hline RRIC 100 & B0-1 & 9 & 2580 \\
& B0-2 & 10 & 2781 \\
& B1-1 & 7 & 2007 \\
RRIC 102 & B1-2 & 1 & 299 \\
& B0-1 & 4 & 917 \\
& B0-2 & 7 & 2132 \\
RRIC 121 & B1-1 & 4 & 695 \\
& B1-2 & - & - \\
& B0-1 & 10 & 3030 \\
& B0-2 & 11 & 2901 \\
RRIC 130 & B1-1 & 7 & 2159 \\
& B1-2 & 2 & 663 \\
& B0-1 & 6 & 1641 \\
Total & B0-2 & 2 & 522 \\
\hline
\end{tabular}

Survey was begun early in the morning at the time of tapping, observing each tree with tappers. Tapping cut of each tree was examined for any signs of the incidence of TPD and the affected trees are categorised symptomatically (i.e. TPD trees with out-growths, with cracks, partial dry or TPD trees without external symptoms). The topography (rank $1-4$, respectively $<10^{\circ}, 10-30^{\circ}, 30-45^{\circ} \&>45^{\circ}$ slope), rockiness (rank 1-4, respectively no, few, medium and highly rocky), soil characteristics and the distribution of TPD trees were also recorded. In addition to field observations, monthly tapping days, intake per tapper and yield per hectare were also recorded for each site for a period of three years. Qualitative data on the tappers' knowledge of TPD disorder were also gathered from the relevant tappers through the informal checklist based interviews, in addition to the above primary and secondary data.

Percentage yield loss due to TPD was calculated based on the annual yield of a healthy tree and the $\%$ full dry and partial dry trees of a given clone. Data were analysed with 'Modelling of 
Tapping panel dryness of rubber

binomial proportions' in the Genstat package. Frequency procedure in SAS package was used to analyse the categorical data of clone, tapping panel, immature period, tapping system, range of tapping days, land slope and rockiness.

\section{Results}

Incidence of tapping panel dryness was tested with the factors: clone, present tapping panel, immature period, girth of healthy and affected trees, average annual yield, tapping system, number of tappings per year, rockiness and slope of the land, by a survey. Results were summarised as follow:

Fig. $1 a$. shows that the \% TPD (full + partial) per panel basis, was high in clones RRIC $100(22.5 \%)$ and RRIC $102(19.7 \%)$ compared to RRIC 121 $(14.5 \%)$ and RRIC $130 \quad(15.8 \%)$ irrespective to the age of the plant. Generally in any clone, the incidence of TPD was low in the virgin panel $\mathrm{B} 0-1$ $(8.0 \%)$ and increased with the advancement of the tapping panel from $\mathrm{B} 0-1$ to $\mathrm{B} 1-2$ (28.9\%; Fig. $1 b, c)$. On average, $40 \%$ of the dry trees were partial dry irrespective to the clone and tapping panel (Fig. 1c).

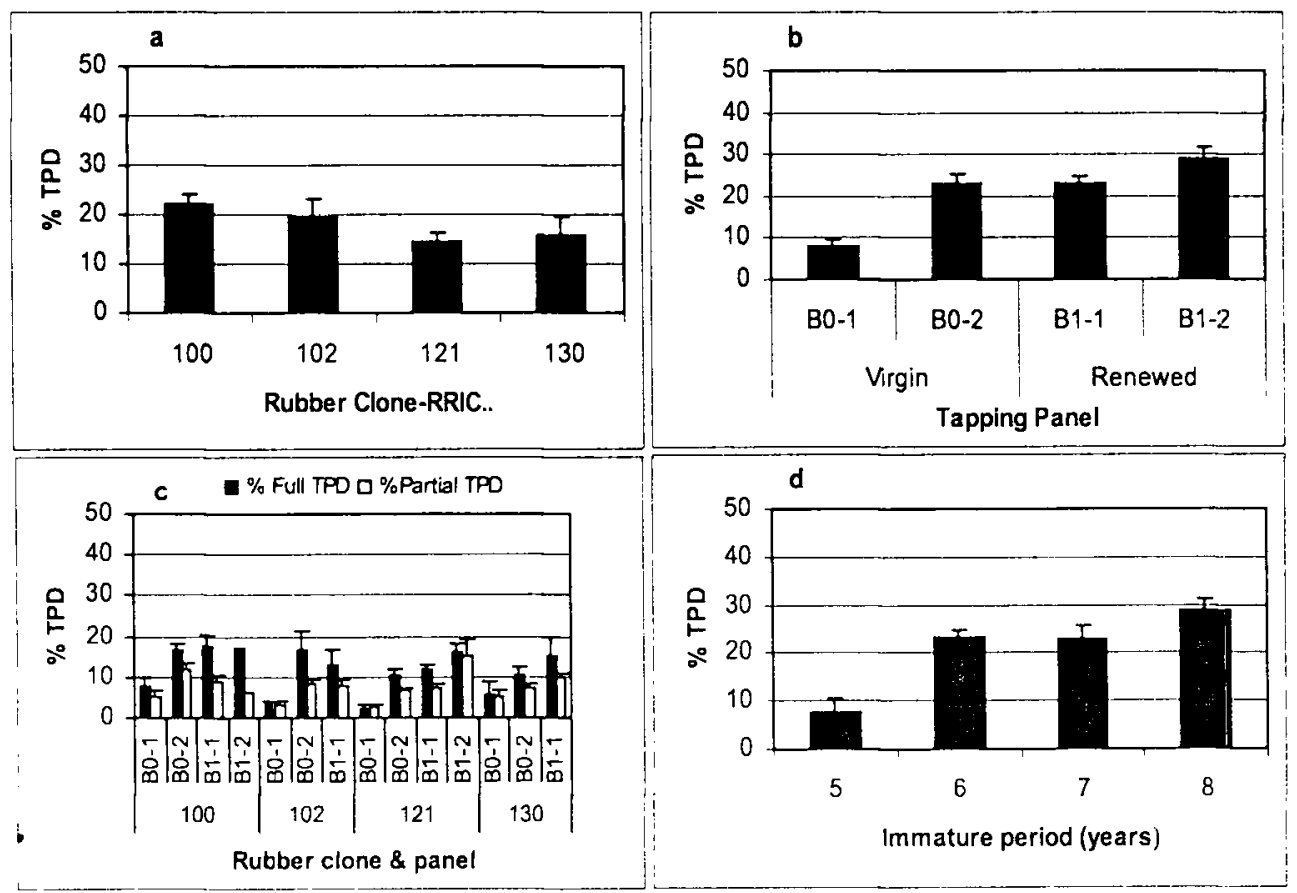

Fig. 1. Summary of the Tapping Panel Dryness (TPD) of rubber on, a. clone, b. tapping panel, c. \% full and partial TPD and d. immature period of plantation. Data are presented for total of 85 tapping blocks of $275-400$ trees per block 


\section{A M W K Senevirathna et al.}

Percentage TPD was increased with the time taken to reach the tappable girth (immature period; Fig. 1d). When the immature period staggered from 5 to 8 years, the incidence of TPD increased by 3.6 fold. Estimated \% TPD with age and yield of plants using binomial proportion modelling showed an exponential increase in the incidence from $6.4 \%$ to $36.8 \%$, respectively from 6 to 22 years of age (Fig. $2 a$ ), and with increasing yield (Fig. $2 b$ ). Similarly, \% TPD estimated using the same model, was found to increase with increasing stem girth measured at $1.5 \mathrm{~m}$ height of both affected and unaffected trees (Fig. 2c,d).
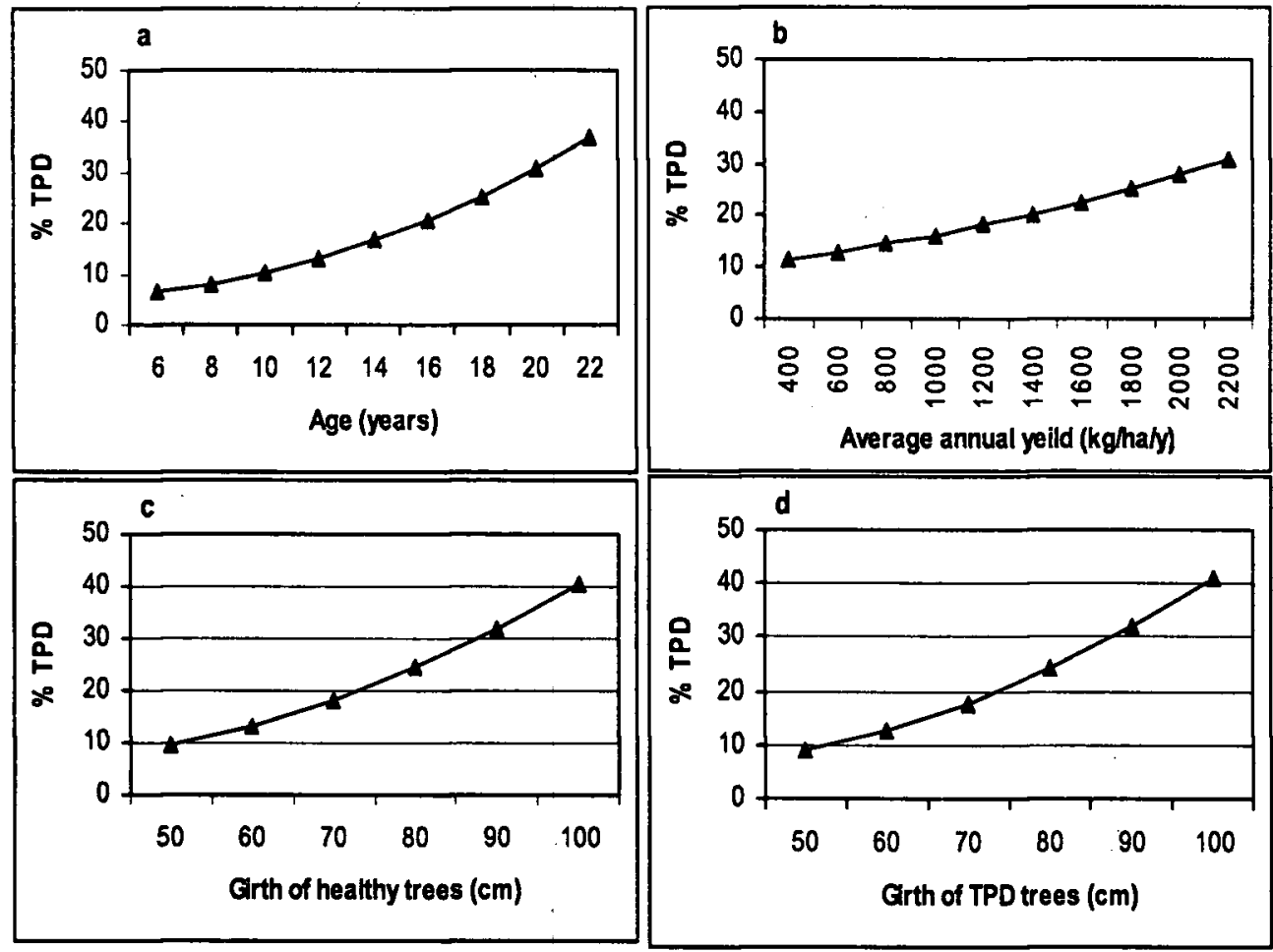

Fig. 2. The effect of Tapping Panel Dryness (TPD) of rubber on, a. age of plantation, b. average annual yield, c. girth of healthy trees and d. girth of TPD trees. Data are shown for total of 85 tapping blocks of $275-400$ trees per block. 
Tapping panel dryness of rubber

The tapping system implemented had a significant effect $(p<0.001)$ on the incidence of TPD and it was $4 \%$ less in the low frequency tapping system of $1 / 2$ $\mathrm{SD}_{3}$ ( $1 / 2$ spiral cut, once in 3 days) compared to the $1 / 2 \mathrm{SD}_{2}(1 / 2$ spiral cut, every other day) system (Fig. $3 a$ ). It was further evident by the figure $3 b$ where the $\%$ TPD was less $(6 \%)$ when total tapping days of a year was less than 250 compared to the higher rates of tappings per year. Land characteristics revealed that TPD percentage was similar and higher $(20 \%)$ in land slope categories of $<10^{\circ}$ and $30-45^{\circ}$ compared to the $10-30^{\circ}$ slope category (Fig. 3c), whilst degree of rockiness of land did not show a remarkable pattern (Fig. $3 d$ ).
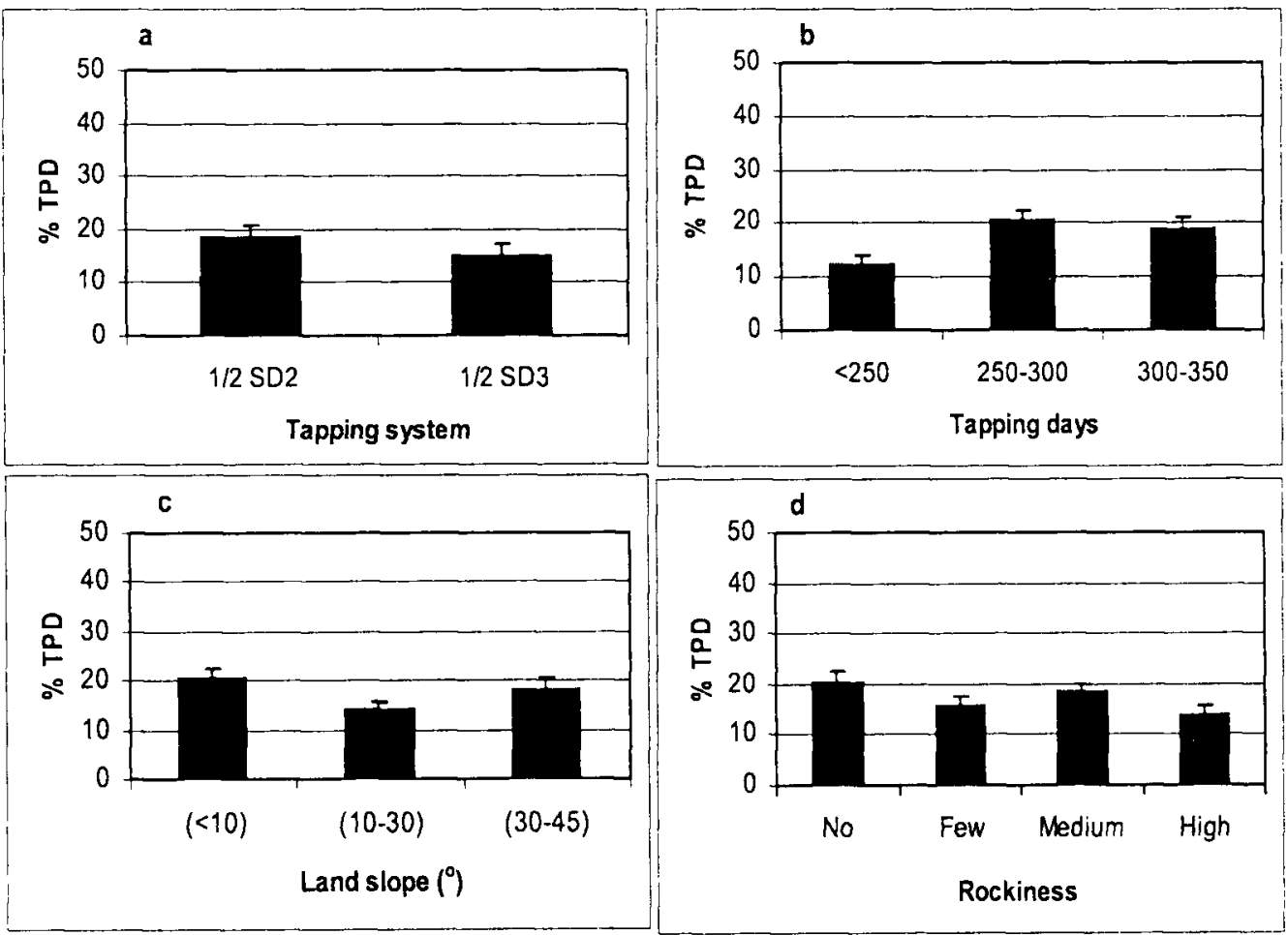

Fig. 3. The effect of Tapping Panel Dryness (TPD) of rubber on, a. tapping system, b. range of annual tapping days, $\mathbf{c}$. land slope category and $\mathbf{d}$. rockiness of the land. Data are shown for total of 85 tapping blocks of 275-400 trees per block 


\section{A M W K Senevirathna et al.}

Figure $4 a$ shows different categories of TPD and their proportions came across from the survey, irrespective to the clone and age of the plant. The majority of plants were without external symptoms $(\mathrm{N} / \mathrm{S}$; $51.8 \%$ ) besides dryness of the tapping panel (Fig. 4a). TPD trees with outgrowths $(0 / \mathrm{G})$ were the lowest $(3.0 \%)$ whilst, $43 \%$ of the affected trees were with bark necrosis (B/N) showing external bark cracks. Of the surveyed tapping blocks, $52.4 \%$ of the sites were with TPD trees scattered in the site while $47.6 \%$ with clusters of affected trees (Fig. 4b). However, when concem the number of affected trees, $58 \%$ of trees were in clusters while $42 \%$ were scattered (Fig. $4 b$ ).

The estimated average yield loss per tapping panel of RRIC 100,102, 121 and 130 were $18.7,14.5,14.3$ and $13.8 \%$, respectively (Fig. 4c). From the nonleading interviews made with relevant tappers during the survey, about $70 \%$ of tappers were with the idea that this disorder is mainly caused by tapping of nubber trees while they are wet or tapping during rains. About $20 \%$ of tappers were of the view that TPD is caused by high intensity of tapping and the rest mentioned other causes such as diseases, low nourishments etc. as the causes for TPD (data arc not shown).
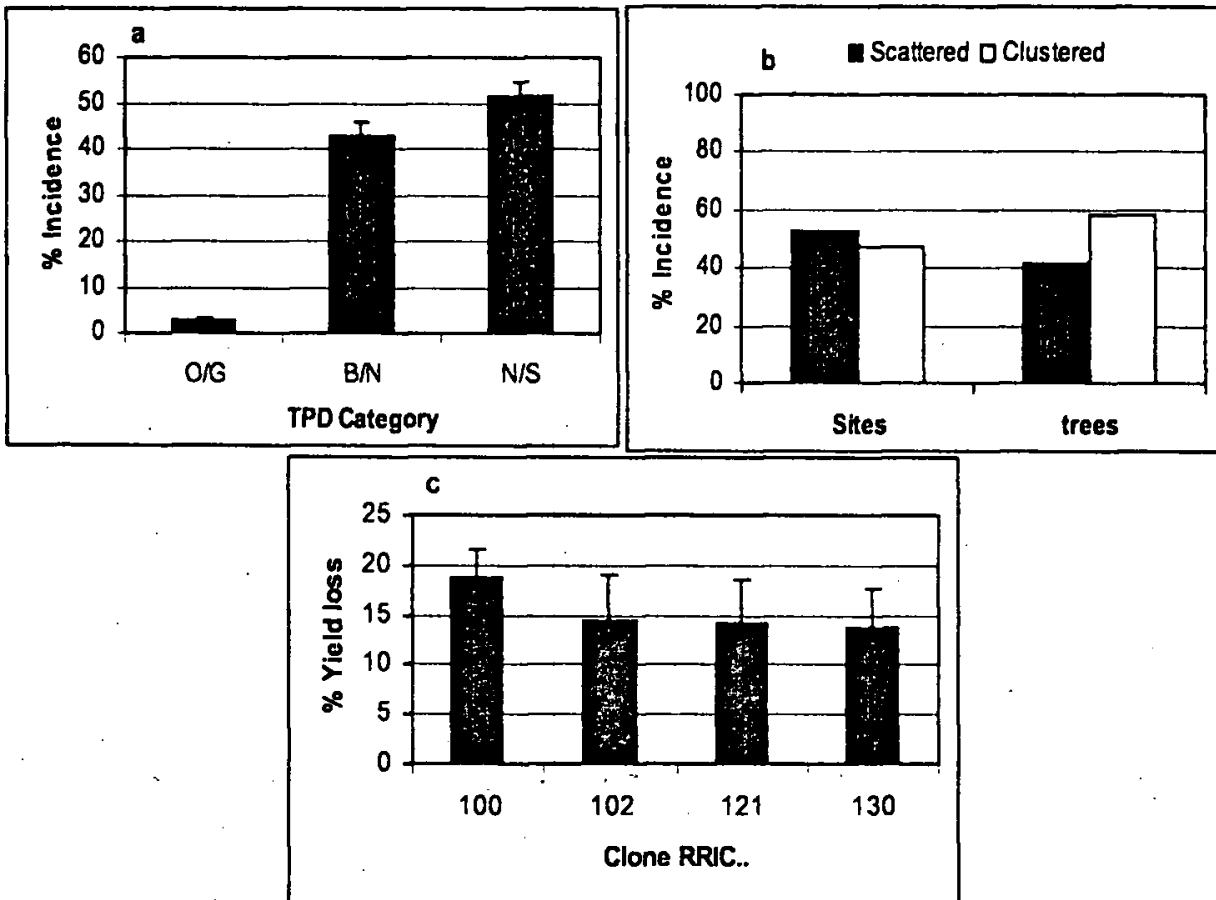

Fig. 4. a. Degree of the different categories of TPD viz, with out-growth $(\mathrm{O} / \mathrm{G})$, with bark necrosis $(B / N)$, without extemal symptoms except panel dryness (N/S), b. distribution patterns of affected trees and c. Estimated \% yield loss in different clones due to TPD. Data are presented for total of 85 tapping blocks of 275400 trees per block. 
Tapping panel dryness of rubber

Discussion

Plant related, histological, physiological, biochemical and molecular biological factors that are involved in the disorder of tapping panel dryness of rubber have been reported by a number of authors (Prematillaka et al., 1985; Wickremasinghe et al., 1987; Yusof et al., 1995; Wu et al., 1997; Thomas et al., 1998; Krishnakumar et al., 1999; Tian and Hao, 1999; Hamzah et al., 2000), but records of external factors are limited. Furthermore, the clonal differences in susceptibility to TPD had been reported for some early recommended clones (de Soyza et al., 1983; Gohet et al., 1997; Omokhafe and Aniamaka, 2000), but the situation of this disorder largely varies genotypically and environmentally. Therefore, it is important to quantify the incidence of TPD with respect to clone and its environment.

According to the survey results, TPD incidence (full + partial) was comparatively high in RRIC 100 (22.5\%) and RRIC 102 (19.7\%) clones being under the current tapping practices in Sri Lankan plantations (Fig. 1a); of the dry trees, partial dry percentage was 35 and $38 \%$ for the two clones, respectively. From an earlier survey done, RRIC 100 trees which were only below 10 years of tapping showed about $8 \%$ of TPD (de Soyza et al., 1983); however, the frequency of incidence of the other clones used for the survey has not been recorded previously. Since about $40 \%$ of the rubber lands are planted with RRIC 100 at present, TPD seem to be one of the serious problems leading to low productivity in the country. Although survey results showed comparatively low incidence of TPD in clones RRIC 121 and RRIC 130 (Fig. 1 a), continuous monitoring of trees for the incidence of TPD showed a higher intensity (over $30 \%$ ) in RRIC 130 within 3 years of tapping in the first virgin panel in some sites (Senevirathna, 2006). This is mainly due to the high intensity of tapping over the recommended frequency for the clone. This indicates that over exploitation causes the increase of TPD. This was further evident by low TPD under low frequency tapping systems (Fig. 3a). Therefore, low frequency tapping systems $\left(1 / 2 \mathrm{SD}_{3}\right.$ etc. $)$ are more suitable to minimise the incidence of TPD. Causes that weaken the growth of plants might have a greater effect on the incident of TPD, as reflected by increasing the \%TPD with staggering the immature period from 5 to 8 years (Fig. 1d). It might be due to the use of poor quality planting material or/and poor immature upkeep of plantations. Therefore, the use of good quality planting materials at the beginning and implementation of correct management practices throughout are essential to shorten the immature period and hence to minimise this disorder.

External morphology of TPD affected trees showed that majority of 


\section{A M W K Senevirathna et al.}

trees were without external symptoms besides dryness of the tapping cut, whilst a few (3\%) trees were with abnormal out growth on the trunk, and the latter might be due to abnormal cell division and enlargement. TPD trees showing bark necrosis (Fig. 4a) are the irreversible type as observed by Jacob et al. (1994). Senevirathna (2006) has shown some other different categories of dry trees such as, 'throughout partial dry', 'throughout fully dry', 'conversion of partial to full dry' and 'recovered' trees. Therefore, the fluctuation of \%TPD with time is expected, because of the differences in rates of onset and recovery of dry trees with time. Of these clones, the recovery percentage was less than that of conversion of partial to full dryness (Senevirathna, 2006). This is one of the reasons for exponential increase of TPD percentage from the tapping panel $\mathrm{B} 0-1$ to $\mathrm{Bl}-2$ and with the age of the plant (Fig. 1b, 2a). Similar exponential increase in TPD has been observed with girthing of plants of both affected and non-affected trees (Fig. $2 c, d)$ and with the yield of plants (Fig. 2b) which was reflected by the behaviour with age of the plant (Fig. $2 a$ ). Since TPD affected trees are not tapped for a considerable period, rate of girthing is high in those trees. Therefore, the girth of affected trees is high compared to the healthy trees.

There was no clear pattern of distribution of affected trees as shown in the Fig. $4 b$. Unexpectedly, the \% TPD was high in lands of less than $10^{\circ}$ gradient and in the sites where there were no rocks (Fig. 3c,d) compared to the other land categories. This is because, a number of shallow/ water logging/ flooding areas where the incidence of TPD was high, come under these two land categories. This is an indication that trees in those land categories are highly prone to TPD. This may be due to the physiological changes in such plants due to low root aeration or/and nutrient leaching. Therefore, such lands should be avoided as much as possible in future planting programmes. Furthermore, any stress factors that affect plants should be eliminated as far as possible in order to minimise the TPD disorder.

Since rubber tappers are the important regular observers of the trees and the environment, their observations are of prime importance in assessment of the degree and factors leading to this disorder. It was noticed that $70 \%$ of tappers are of the view that TPD is mainly caused by tapping on wet panels, and a future study on this aspect can be useful.

\section{Acknowledgements}

Authors first wish to
acknowledge the Council for Agricultural Research Policy (CARP) in Sri Lanka for granting financial assistance for this research project (12/478/358). Our thanks are also extended to Estate Managers, staff and the tappers who gave their immense corporation to conduct this research 
Tapping panel dryness of rubber

successfully. We sincerely thank Dr. (Mrs.) Wasana Wijesuriya, Biometrician of the RRISL for her help in analysing data and the supporting staff of RRISL who helped in various ways for the success of this research project.

\section{References}

De Soyza, A G A, Samaranayake, C, Abeywardene, V, Jayarathna, A H R and Wilbert, S (1983). A survey on the incidence and pattern of distribution of the brown bast disease of Hevea in Sri Lanka. Journal of the Rubber Research Institute of Sri Lanka 61, 1-6.

Gohet, E, Dian, K, Prevot, J C, Obouayeba, S, Clement, A, d'Auzac, J, Keli, J Z and Jacob, J L (1997). Relation between clone type, latex sucrose content and the occurrence of tapping panel dryness in Hevea brasiliensis. Workshop on tapping panel dryness in Hevea brasiliensis, Hainan, China, 2930 April 1997. Intemational Rubber Research and Development Board, United Kingdom. pp. 21-27.

Hamzah, S, Xiao, X, Luo, S, Chan, J L and Yeang, H Y (2000). Protein marker for tapping panel dryness identified as the small nubber particle protein (Hev b3). Journal of the Rubber Research Institute of Sri Lanka 3 (1), 42-52.

Jacob, J L, Prevot, J C and Lacrotte, R (1994). L'encoche seche chez Hevea brasiliensis. Plantations, Recherche, Developpment 1, 15-24.

Krishnakumar, R, Sreelatha, S, Thomas, M, Gopalkrishnan, J, Jacob, J and Sethuraj, M R (1999). Biochemical composition of scift bark tissues in Hevea affected by tapping panel cryness. Indian Journal of Natural Rubber Research 12 (1-2), 92-99.

Omokhafe, K O and Aniamaka, E E (2000). Heritability estimates of tree dryness and correlation with latex parameters in Hevea brasiliensis. Journal of the Rubber Research Institute of Sri Lanka 83, 17-22.

Prematillaka, S P, Yapa, P A J and Bamunuarachchi, A (1985). Serum protein patterns in healthy and brown bast affected trees of Hevea. Journal of the Rubber Research Institute of Sri Lanka 64, 7-12.

Senevirathna, A M W K (2006). Identification of physical factors affecting tapping panel dryness (TPD) of rubber (Hevea brasiliensis Muell Arg.), and some biochemical changes at the onset of tapping panel dryness: Terminal Report of CARP Project 12/478/358, Rubber Research Institute of Sri Lanka. pp. 29.

Thomas, M, Sreelatha, S, Simon, S P, Nair, $\mathrm{N}$ U, Thomas, $\mathrm{K}$ U, Jacob, J and Sethuraj, M R (1998). Availability of photosynthates and occurrence of tapping panel dryness syndrome in Hevea brasiliensis. Developments in Plantation Crop Research, Proceedings of the $12^{\text {th }}$ Symposium on Plantation Crops, Kottayam, India, 27-29 November 1996. Rubber Research Institute of India.

Tian, W M and Hao, B Z (1999). Protein storing cells with a $67 \mathrm{kDa}$ protein in regularly tapped Hevea trees and in trees affected by tapping panel dryness. Journal of the Rubber Research Institute of Sri Lanka 2 (3), 183-191.

Wickremasinghe, S I, Yapa, P A J and De Soyza, T V W (1987). Accumulation of 


\section{A M W K Senevirathna et al.}

free proline in bark and latex of Hevea brasiliensis affected by brown bast. Journal of the Rubber Research Institute of Sri Lanka 67, 9-17.

Wu, J L, Tan, H Y and Tian, W M (1997). Tapping panel dryness syndrome in Hevea brasiliensis. associated with wounds in the roots. Indian Journal of Natural Rubber Research 10 (1-2), 102-106.

Yusof, F, Arija, M A S, Ghandimathi, H, Hamzah, Z, Sivakumaran, $S$ and Yeang, H Y (1995). Changes in some physiological latex parameters in relation to over exploitation and the onset of induced tapping panel dryness. Journal of Natural Rubber Research 10 (3), 182-198.

Address for correspondence: Dr A.M.W.K. Senevirathna, Botanist, Rubber Research Institute of Sri Lanka, Dartonfield, Agalawatta, Sri Lanka.

E-mail: wasan@sltnet.lk, dirrri@sltnet.lk 